Review

\title{
Stress-Corrosion Interactions in Zr-Based Bulk Metallic Glasses
}

\section{Petre Flaviu Gostin 1,*, Dimitri Eigel ${ }^{1}$, Daniel Grell ${ }^{2}$, Margitta Uhlemann ${ }^{1}$, Eberhard Kerscher ${ }^{\text {, }}$ Jürgen Eckert ${ }^{1,3}$ and Annett Gebert ${ }^{1}$}

1 Leibniz-Institute for Solid State and Materials Research IFW Dresden, Dresden D-01171, Germany; E-Mails: d.eigel@ifw-dresden.de (D.E.); m.uhlemann@ifw-dresden.de (M.U.); j.eckert@ifw-dresden.de (J.E.); a.gebert@ifw-dresden.de (A.G.)

2 Materials Testing, TU Kaiserslautern, Gottlieb-Daimler-Strasse, Kaiserslautern D-67663, Germany; E-Mails: daniel.grell@mv.uni-kl.de (D.G.); kerscher@mv.uni-kl.de (E.K.)

3 Institute of Materials Science, Faculty of Mechanical Science and Engineering, TU Dresden, Dresden D-01062, Germany

* Author to whom correspondence should be addressed; E-Mail: f.p.gostin@ifw-dresden.de; Tel.: +49-351-465-9767; Fax: +49-351-465-9452.

Academic Editors: K. C. Chan and Jordi Sort Viñas

Received: 7 May 2015 / Accepted: 10 July 2015 / Published: 15 July 2015

\begin{abstract}
Stress-corrosion interactions in materials may lead to early unpredictable catastrophic failure of structural parts, which can have dramatic effects. In Zr-based bulk metallic glasses, such interactions are particularly important as these have very high yield strength, limited ductility, and are relatively susceptible to localized corrosion in halide-containing aqueous environments. Relevant features of the mechanical and corrosion behavior of $\mathrm{Zr}$-based bulk metallic glasses are described, and an account of knowledge regarding corrosion-deformation interactions gathered from ex situ experimental procedures is provided. Subsequently the literature on key phenomena including hydrogen damage, stress corrosion cracking, and corrosion fatigue is reviewed. Critical factors for such phenomena will be highlighted. The review also presents an outlook for the topic.
\end{abstract}

Keywords: metallic glasses; amorphous alloys; zirconium alloys; corrosion; stress corrosion cracking; corrosion fatigue; hydrogen damage; shear bands; mechanical behavior 


\section{Introduction}

In the last few decades a remarkably growing understanding of the glass-forming ability (GFA) of metallic alloy systems and the optimization of casting techniques have enabled the production of bulk metallic glasses with up to several centimetres in thickness. This makes this new class of material very interesting for engineering applications, e.g., in electronic packaging, pressure sensors, sportive equipment, biomedical devices, or MEMS [1]. Compared to crystalline alloys, metallic glasses exhibit unusual chemical compositions and unique short- and medium-range ordered (SRO/MRO) structures. Similar to inorganic glasses, with their ideally single-phase nature, they lack defects like grain boundaries, dislocations, or second phases. In consequence, this particular alloy state yields some exceptional properties. Most importantly, the topology of SRO and MRO controls the material's response to mechanical stress [2]. The room temperature mechanical performance is characterized by superior hardness and ultimate strength as well as large elastic strain limits enabling large reversible mechanical energy storage, for instance. But upon straining beyond the elastic limit metallic glasses fail with only limited macroscopic plastic deformation. In absence of the possibility for dislocation mediated crystallographic slip, the deformation mode of metallic glasses is very heterogeneous; it is based on the formation of localized shear bands, which result in catastrophic failure due to uninhibited shear band propagation. Meanwhile, the underlying deformation processes have been intensively studied in dependence on a wide parameter field and detailed mechanistic descriptions have been provided $[3,4]$. New concepts refer to improvement of plasticity by retarding shear band propagation, e.g., by development of "ductile glasses" and "glass-matrix composites" with different length-scales of constituent phases [5] or by mechanical pre-treatments like shot-peening [6] or cold rolling [7] causing shear-band multiplication.

For metallic glasses the resistance against crack propagation determining fracture toughness and fatigue resistance is a critical aspect [8]. Due to their single-phase, quasi-brittle nature, behaviour similar to that of oxide or silicate glasses is expected, but several metallic glasses behave nearly like crystalline alloys. Studies dealing with those phenomena are still limited and the results obtained so far are not very consistent. Besides limited availability of material and use of non-standardized testing methods this is mostly attributed to the large number of influencing parameters [9]. Not only materials properties were identified to be important, but also in particular environmental influences causing chemical reactions in the crack regions. Contradicting traditional opinions, recent studies have clearly demonstrated that bulk metallic glasses are prone to corrosion degradation mainly due to localized dissolution reactions [10]. Moreover, in particular the early-late transition metal glass formers are good hydrogen absorbers based on occupation of the interstitial sites of the SRO units by hydrogen atoms [11]. The superposition of those environmentally induced reactions to stress-driven degradation processes may give rise to environmentally induced cracking phenomena like hydrogen damage, stress corrosion cracking, and corrosion fatigue.

Studies of corrosion-deformation interactions in metallic glasses have been reviewed in several publications [10,12-15]. However, those review papers focused mostly on Fe- and Ni-based metallic glasses. The present review is dedicated to $\mathrm{Zr}$-based metallic glasses, which have gained increasing attention in the last two decades and which form at present the most prominent alloy family of metallic glasses. 


\section{Mechanical Properties at Room Temperature}

Macroscopic mechanical properties of multi-component Zr-based alloys mostly obtained from uniaxial compression tests are in typical ranges of 70-96 GPa Young's modulus, 1400-1900 MPa ultimate strength and around $2 \%$ elastic limit, given for selected standard alloys $\mathrm{Zr}_{55} \mathrm{Cu}_{30} \mathrm{Al}_{10} \mathrm{Ni}_{5}$, $\mathrm{Zr}_{57} \mathrm{Cu}_{15.4} \mathrm{Ni}_{12.6} \mathrm{Al}_{10} \mathrm{Nb}_{5}$ (Vitreloy 106) and $\mathrm{Zr}_{41.2} \mathrm{Ti}_{13.8} \mathrm{Cu}_{12.5} \mathrm{Ni}_{10} \mathrm{Be}_{22.5}$ (Vitreloy 1) [1]. Zr-based alloys have been the main targets for principal analyses of deformation mechanisms of metallic glasses with special emphasis on the processes of shear band nucleation and propagation and for development of concepts for property improvements [3-7,16]. Recent studies focused on multi-axial loading conditions in bending tests. Wang et al. [17] described the inhomogeneous distribution of residual stresses in bent $\mathrm{Zr}-\mathrm{Ti}-\mathrm{Al}-\mathrm{Cu}-\mathrm{Ni}$ glass specimen and identified a high sensitivity of hardness to it, which is more pronounced in regions under tension. Zhao et al. [18] analyzed shear deformation mechanisms. The inhomogeneous stress distribution in a bent glass specimen led to regions which were still elastic whereby for others at the tension surface the critical shear stress was reached resulting in a regular pattern of shear bands. Introduction of significant stress gradients in a metallic glass specimen yields a larger plasticity than under uniaxial tension. Following this concept the surface imprinting technology was developed as new approach for making glasses more ductile [19].

\section{Intrinsic Plasticity and Toughness of Metallic Glasses}

Plasticity plays a key role in environmentally induced cracking of metals/alloys, in contrast to inorganic glasses and ceramics, which are brittle and crack by reaction of the environment with highly stressed bonds at an atomically sharp crack tip [20,21]. Metallic glasses may be considered as quasi-brittle materials because they do not possess sufficient intrinsic micro-mechanisms to mitigate high stress concentrations at crack tips. This is accompanied by lack of strain hardening and crack propagation barriers like grain boundaries and should result in "ideal brittle fracture" behavior. The same fact was derived for inorganic glasses based on a series of chemical bond rupture events and absence of plastic deformation giving rise to low toughness [8]. However, Lewandowski et al. [22] revealed that similar as for polycrystalline metals, for metallic glasses a correlation exists between the fracture energy $\mathrm{G}$ and the $\mu / B$ ratio ( $\mu$-elastic shear modulus, $B$-bulk modulus) with a critical ratio $\mu / B_{\text {crit }}=0.41-0.43$, which determines their intrinsic plasticity $($ low $\mu / B)$ or brittleness $($ high $\mu / B)$. This relation can also be expressed in terms of the Poisson's ratio $v$, with $v_{\text {crit }}=0.31-0.32$ and $v>v_{\text {crit }}$ indicating certain glass toughness. For example Mg-based glasses are "brittle", whereas Zr-based glasses are "tough" with some variations among the particular compositions. Cast Zr-based glasses exhibit capability for high plasticity strongly localized in narrow shear bands. A high strength level combined with capacity for local plastic flow can give rise to high fracture toughness. But macroscopic plasticity in tension remains limited since fracture occurs under tension only in one dominant shear band. The fracture surface shows the characteristic vein-like morphology as result of the viscosity drop in the shear band. Annealing below the glass transition causing structural relaxation and densification can reduce the toughness of certain Zr-based BMGs. 


\section{Corrosion Aspects}

The corrosion behavior of metallic glasses is determined by their composition, i.e., the reactivity of their constituent elements, by their thermodynamic metastability and their ideal single-phase chemically and structurally homogeneous nature. $\mathrm{Zr}-\mathrm{Cu}$-based bulk glass formers have been a main target for fundamental corrosion studies in different aqueous media. In a wide $\mathrm{pH}$ value range excellent passivation ability was detected [10]. This is based on the competitive processes of $\mathrm{Cu}$ dissolution and formation of barrier-type thin valve-metal (e.g., $\mathrm{Zr}, \mathrm{Al}, \mathrm{Ti}, \mathrm{Nb}$ ) oxide films which is determined by the Cu:valve-metal atomic ratio of the alloy and by the surface finishing state [23].

Zr-based glassy alloys exhibit in halide-containing solutions a high sensitivity for pitting which comprises local dissolution of valve-metal components and enrichment of $\mathrm{Cu}$-complexes. TEM studies revealed $\mathrm{Cu}$-rich nanocrystals at pit walls which govern the pit morphology evolution by (i) protecting capped areas against dissolution and (ii) speeding the dissolution of uncapped areas by local galvanic cells. This gives rise to rapid pit growth and low repassivation. Their pitting susceptibility and repassivation ability can be significantly influenced by alloying elements [24-29]. In a recent study, both these properties were found to depend strongly on $\mathrm{Cu}$ concentration [30]. High pitting resistance is achieved by decreasing the $\mathrm{Cu}$ and increasing the valve metals contents. The pitting susceptibility of samples prepared under real casting conditions is related with the presence of chemical defects, i.e., crystalline inclusions, or physical defects, e.g., air pockets or pores [10,31,32].

\subsection{Pitting at Local Surface Defects}

It is well known that stress corrosion cracking often initiates at preexisting surface discontinuities/defects or corrosion-induced features, e.g., pits [33]. Before attempting to understand the role of such surface defects on the stress corrosion cracking initiation process, it is useful to first evaluate how these influence the corrosion behavior of Zr-based BMGs, especially pitting. In a recent study, Vickers micro-indents were used as model surface defects to study their impact on the pitting susceptibility of a typical $\mathrm{Zr}$-based $\mathrm{BMG}$, i.e., $\mathrm{Zr}_{59} \mathrm{Ti}_{3} \mathrm{Cu}_{20} \mathrm{Al}_{10} \mathrm{Ni}_{8}$ [34]. Multiple micro-indents were created by applying various loads from 25 to $2000 \mathrm{~g}$ on a mechanically polished surface. The pitting susceptibility was evaluated by anodic potentiodynamic polarization in $0.01 \mathrm{M} \mathrm{Na} 2 \mathrm{SO}_{4}+0.01 \mathrm{M} \mathrm{NaCl}$. As shown in Figure 1, for the reference as-polished state and for $200 \mathrm{~g}$ micro-indents no pitting takes place, whereas for $2000 \mathrm{~g}$ micro-indents pitting clearly takes place at a potential of about $0.44 \mathrm{~V} v s$. SCE. Subsequent SEM analysis revealed pits were located preferentially inside or at the rim of micro-indents (see inset in Figure 1). This demonstrates that isolated mechanical surface defects can have a significant detrimental effect on the pitting susceptibility of Zr-based BMGs.

As mentioned above, one of the limitations of metallic glasses is their inhomogeneous plastic deformation behavior in shear bands and lack of strain hardening, which hinders their use in structural applications. Shot-peening induces surface compressive residual stresses and favors nucleation of shear bands near the surface, which in turn translates into larger macroscopic plasticity in compression and in bending [6]. The process of shot-peening severely alters not only the stress field and the surface topography, but also the structure of the metallic glass to a depth of up to $150 \mu \mathrm{m}$ [35]. This in turn causes a slight improvement of spontaneous passivity in halide-free environments [36]. However, after 
prolonged shot-peening a decrease of the pitting resistance was detected. Figure 2 shows a SEM image of a shot-peened bulk glassy $\mathrm{Zr}_{59} \mathrm{Ti}_{3} \mathrm{Cu}_{20} \mathrm{Al}_{10} \mathrm{Ni}$ alloy sample surface after exposure to $6 \mathrm{M} \mathrm{HCl}$ for several seconds. One large pit and several smaller ones can be seen. Craters formed by shot-peening are preferentially attacked and are fully corroded. It was found that the degradation patterns are driven by local stress fields surrounding the craters and scratches. In conclusion, shot-peening is expected to have antagonistic effects on the environmentally induced cracking of Zr-based BMGs: it increases plasticity which should be beneficial for mitigating stress concentration at crack tips, but at the same time it decreases the resistance to pitting corrosion which can lead to initiation of cracking.

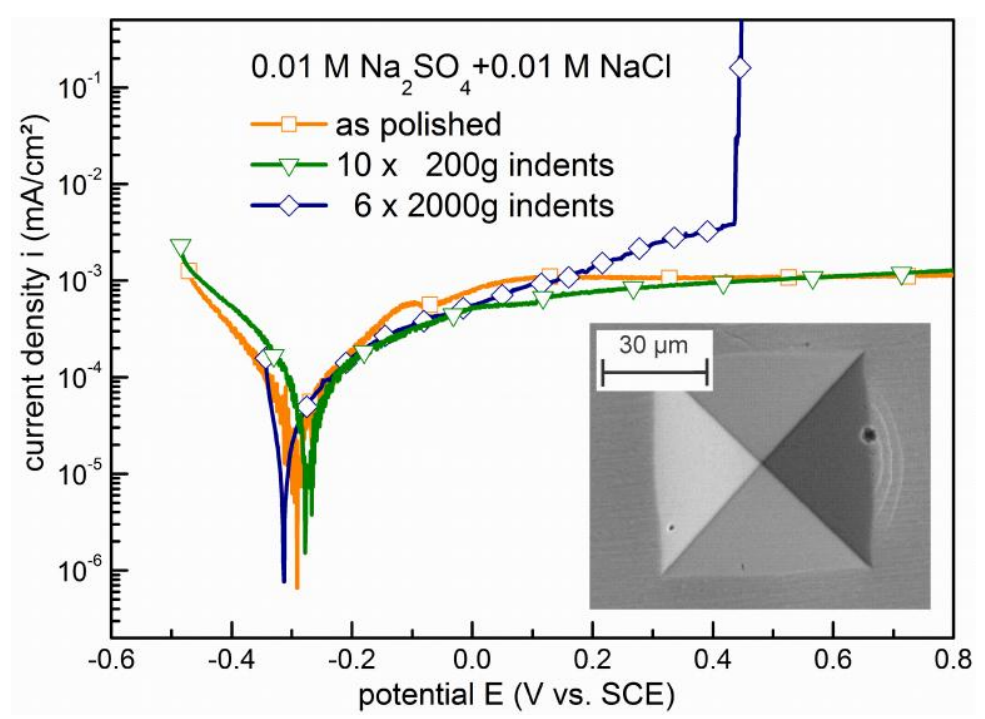

Figure 1. Anodic potentiodynamic polarization curves of bulk glassy $\mathrm{Zr}_{59} \mathrm{Ti}_{3} \mathrm{Cu}_{20} \mathrm{Al}_{10} \mathrm{Ni} 8$ alloy in the as polished state and after applying Vickers micro-indent arrays with two different loads.

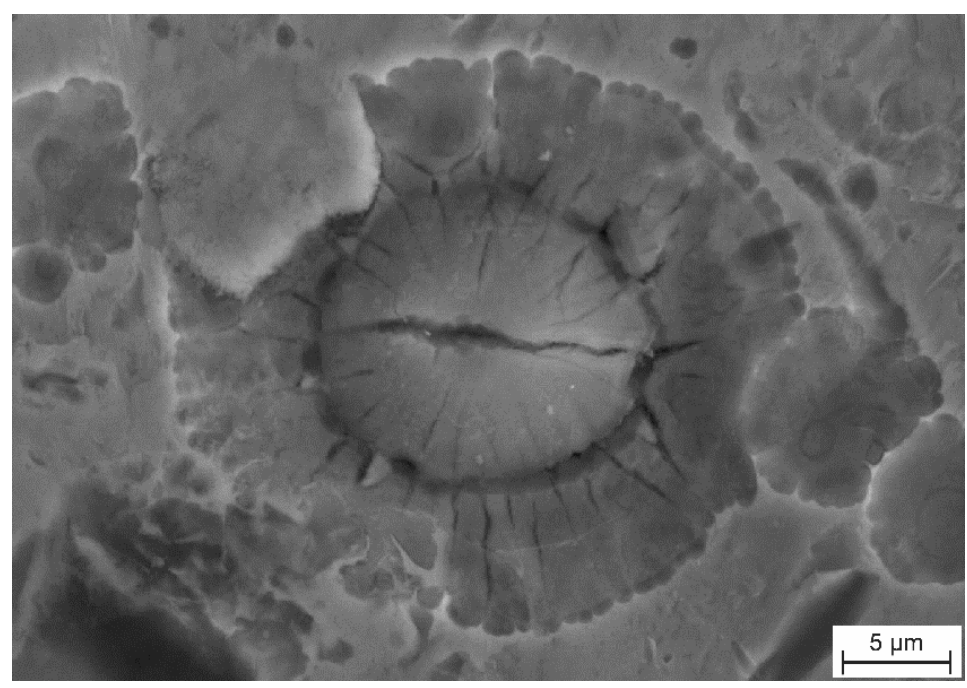

Figure 2. SEM image of a bulk glassy $\mathrm{Zr}_{59} \mathrm{Ti}_{3} \mathrm{Cu}_{20} \mathrm{Al}_{10} \mathrm{Ni}$ i alloy sample surface after shot-peening for $30 \mathrm{~s}$ and subsequent exposure to $6 \mathrm{M} \mathrm{HCl}$ for several seconds. 


\subsection{Pitting at Shear Steps and Shear Bands}

Although shear steps at a surface created by shear banding can be regarded as surface defects, considering the focus of this paper, they are treated separately in this subsection. Already early in the history of metallic glass research, it has been recognized that shear bands in metallic glasses can be preferentially etched [37]. More recent studies demonstrated that shear steps at the surface produced by shear banding are preferred initiation sites for pitting corrosion. Gebert et al., carried out uniaxial compression loading to generate multiple shear bands in a bulk glassy $\mathrm{Zr}_{59} \mathrm{Ti}_{3} \mathrm{Cu}_{20} \mathrm{Al}_{10} \mathrm{Ni}$ alloy samples [34]. These samples were subsequently exposed to an aggressive $12 \mathrm{M} \mathrm{HCl}$ solution for 1 to $2 \mathrm{~min}$. As shown exemplarily in Figure 3, pits preferentially initiate at shear steps. This may be explained in terms of the passive film being mechanically broken down along the shear step. Additionally, pits have a tendency to grow along the shear steps creating elongated attack features with a width comparable to that of the heat affected zone of shear bands, i.e., 4-10 $\mu \mathrm{m}$ [38]. In the vicinity of shear bands chemical and structural changes and sometimes crystallization can occur due to the shearing process and the associated heating [39]. Moreover, near shear bands local residual stresses may be expected, which can accelerate dissolution [40]. Similar preferential pitting corrosion at shear steps was observed for the $\mathrm{Zr}_{64.13} \mathrm{Cu}_{15.75} \mathrm{Ni}_{10.12} \mathrm{Al}_{10} \mathrm{BMG}$ [41]. The shear bands/steps were generated by cold rolling. However, preferential pitting at shear steps was observed only in chronopotentiometric tests. No clear preferential pitting occurred under free corrosion conditions, i.e., at the open circuit potential. In this study, structural changes in shear bands, more than the surface shear offset or the residual stresses, were assumed to be the main factor for preferential pitting at shear bands. On the contrary, Wang et al. [42] found for the $\left(\mathrm{Zr}_{62} \mathrm{Cu}_{23} \mathrm{Fe}_{5} \mathrm{Al}_{10}\right)_{97} \mathrm{Ag}_{3} \mathrm{BMG}$ that the shear offset (step), rather than the structural changes in the shear bands, is responsible for pitting initiation. Supporting this conclusion was the observation that preferential pitting does not occur at shear bands when the surface was polished. In conclusion, it is clear that shear steps at the surface of Zr-based BMGs are preferential sites for initiation of pitting corrosion. However, there is disagreement regarding the main reason and further work is necessary to explain this observation.

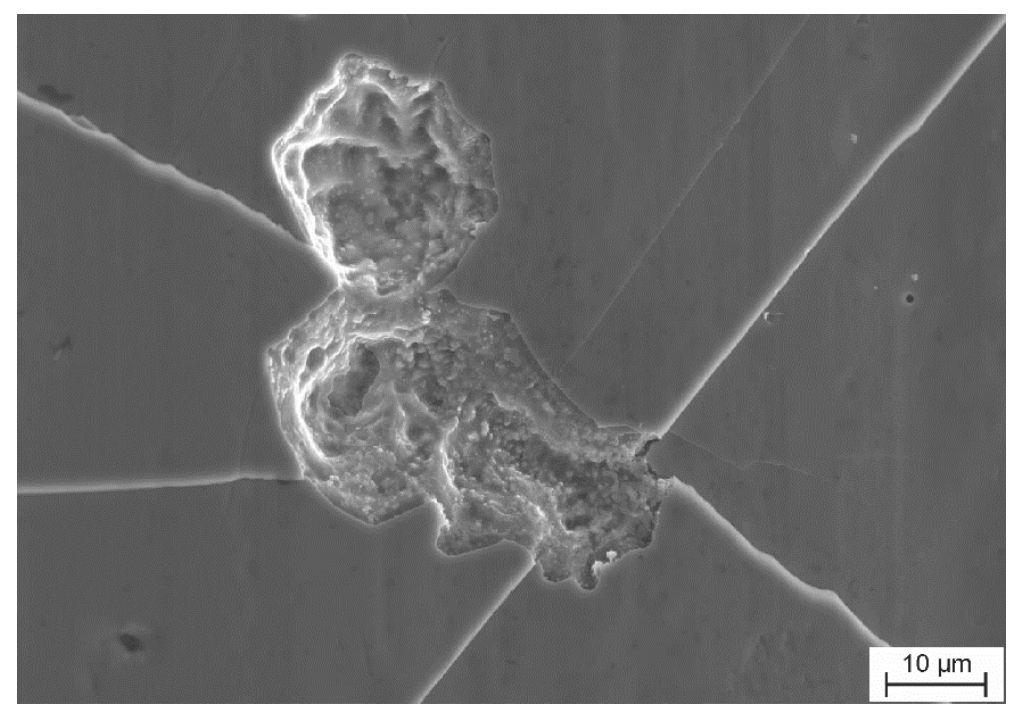

Figure 3. SEM image of a pit on the lateral surface of a bulk glassy $\mathrm{Zr}_{59} \mathrm{Ti}_{3} \mathrm{Cu}_{20} \mathrm{Al}_{10} \mathrm{Ni}_{8}$ alloy sample compressed to fracture. 
In the above paragraph only ex situ studies were presented, i.e., first shear steps were created at the surface of metallic glass specimens by mechanical loading in air and their corrosion behavior was subsequently analyzed in electrolyte. In a very recent work, Grell et al. [43] carried out in situ electrochemical experiments during quasistatic three-point bending of flat bulk glassy $\mathrm{Zr}_{52.5} \mathrm{Cu}_{17.9} \mathrm{Al}_{10} \mathrm{Ni}_{14.6} \mathrm{Ti}_{5}$ alloy (Vitreloy 105) samples in $0.01 \mathrm{M} \mathrm{Na} \mathrm{SO}_{4}$. Open circuit potential as well as potentiostatic measurements reveal clear transients corresponding to the exposure of bare alloy when shear bands create a step at the surface causing breakdown of the passive film followed by repassivation. However, to the authors' knowledge in situ tests of pitting susceptibility during shear step formation have not yet been carried out.

\section{Environmentally Induced Cracking}

Most work related to environmentally induced cracking of Zr-based BMGs was done on hydrogen effects (e.g., [44-52]) and on corrosion fatigue [53-60]. Studies on stress corrosion cracking of Zr-based BMGs are rather scarce $[9,10,13,53,61]$.

According to general knowledge gained from studies on conventional crystalline metals and alloys, as the yield strength increases, the resistance to environmentally induced cracking decreases [62]. If this holds also for metallic glasses, they should have lower resistance to the various types of environmentally induced cracking, e.g., stress corrosion cracking or hydrogen damage.

\subsection{Hydrogen Effects}

Zr-based metallic glasses exhibit significant capability for absorption of hydrogen. Hydrogen atoms occupy interstitial sites in the SRO structure with different energy levels being determined by the local atomic environment and the hydrogen affinity of the constituents. Preferential occupation of interstitial sites of polyhedra formed by $\mathrm{Zr}$ atoms was verified [11,63]. The incorporation of hydrogen leads to a reduction of free volume and the buildup of local strain which retards atomic mobility causing increased internal friction $[64,65]$. When the hydrogen concentration reaches a threshold locally, phase separation into regions of $\mathrm{ZrH}_{x}$ and $\mathrm{Cu}$-rich phases occurs [66,67]. For $\mathrm{Zr}-\mathrm{Al}-\mathrm{Cu}-\mathrm{Ni}$ glasses $\mathrm{H} / \mathrm{M}(\mathrm{M}=$ metal) ratios of up 1.9 were measured and a significant effect on the thermal behavior was detected $[67,68]$. Based on these principal findings strong effects of absorbed hydrogen on crack initiation and propagation processes in Zr-based glasses can be predicted.

Absorbed (pre-charged) hydrogen has significant effects on the mechanical properties of $\mathrm{Zr}$-based BMGs. For different alloy compositions an increase of hardness with increasing hydrogen content in the amorphous structure was evidenced and attributed to a restriction of shear band formation. This was compared with thermal relaxation effects causing embrittlement [34,46,69]. Wang et al. [70] investigated glassy I-shaped notched $\mathrm{Zr}_{57} \mathrm{Cu}_{15.4} \mathrm{Ni}_{12.6} \mathrm{Al}_{10} \mathrm{Nb}_{5}$ (Vitreloy 106) specimen (made from $1.5 \times 10 \times 12 \mathrm{~mm}^{3}$ plates) under sustained tensile load and severe hydrogen charging. Enhanced local shear band nucleation at the notch, but limited growth was observed with increasing charging time and interpreted as enhanced localized plastic flow. Shan et al. [48] observed the damage evolution during 3-point bending of notched bulk glassy $\mathrm{Zr}_{41.2} \mathrm{Ti}_{13.8} \mathrm{Cu}_{12.5} \mathrm{Ni}_{10} \mathrm{Be}_{22.5}$ (Vitreloy 1) samples $\left(2 \times 4 \times 15 \mathrm{~mm}^{3}\right)$ under sustained loading conditions and different hydrogen charging rates. Below a critical current density of $20 \mathrm{~mA} \cdot \mathrm{cm}^{-2}$, hydrogen is incorporated into the amorphous structure without hydride formation or blistering. Initiation 
of hydrogen-induced cracking and hydrogen-induced delayed fracture takes place at a stress value representing $63 \%$ of that required for fracture of uncharged specimens. Above the critical charging rate, blistering and micro-cracking occurred causing a relative stress for crack initiation of $26 \%$. Suh and Dauskardt [44] prepared fatigue pre-cracked CT specimen of this bulk glass (from plates with $3 \mathrm{~mm}$ thickness) and investigated the effect of pre-charged hydrogen on fracture toughness and fatigue crack growth. Increased charging time was found to have a degrading effect on initiation fracture toughness. In contrast, fatigue crack growth rates were found to be retarded with increasing charging time. Microscopic fatigue crack analysis revealed a tortuous and deflected crack path of pre-charged samples in comparison to a straight crack path of uncharged ones. The contradicting results were interpreted as a competition between degradation of the inherent resistance to crack extension and increased crack tip shielding.

In summary, Zr-based metallic glasses exhibit significant capability for absorption of hydrogen, which in turn severely affects their mechanical properties depending on the concentration of absorbed hydrogen. On the one hand, increasing hydrogen concentration leads to increased hardness. On the other hand, hydrogen appears to enhance nucleation of shear bands at notch tips and to decrease the threshold intensity factor. Furthermore, hydrogen has a retarding effect on the crack growth rate under sustained or cyclic loading.

\subsection{Chloride-Induced Stress Corrosion Cracking}

Kawashima et al. [71] conducted slow strain rate $\left(5 \times 10^{-6} \mathrm{~s}^{-1}\right)$ tensile tests on glassy $\mathrm{Zr}-\mathrm{Cu}-\mathrm{Al}(\mathrm{Ni})$ specimens $(3.5 \div 8 \mathrm{~mm}$ diameter rods) in various aqueous electrolytes under free corrosion conditions. A significant reduction in fracture stress from more than 1800 to $880 \mathrm{MPa}$ in $\mathrm{NaCl}$ solution was detected, while this effect was dependent on alloy composition. Cracks were found to initiate at pits. Brittle fracture features were observed close to the crack origin. These were attributed to presumed hydrogen-induced subcritical crack growth. In another study, Schroeder et al. [55] carried out crack velocity measurements on compact tension specimens of the bulk glass forming $\mathrm{Zr}_{41.2} \mathrm{Ti}_{13.8} \mathrm{Cu}_{12.5} \mathrm{Ni}_{10} \mathrm{Be}_{22.5}$ alloy in $0.5 \mathrm{M} \mathrm{NaCl}$ at constant stress and free corrosion conditions. Above a $K_{\text {ISCC, }}$ a sharp increase in crack velocity of several orders of magnitude was observed. This was followed by a plateau at $10^{-5} \div 10^{-4} \mathrm{~m} \cdot \mathrm{s}^{-1}$. It was assumed that crack propagation took place by an anodic dissolution assisted mechanism. Almost identical results were reported by Nakai and Yoshioka [58] for a different Zr-based BMG, i.e., $\mathrm{Zr}_{55} \mathrm{Cu}_{30} \mathrm{Ni}_{5} \mathrm{Al}_{10}$, in 3.5 wt. \% NaCl.

Gostin et al. [61] recently investigated stress corrosion cracking phenomena in bulk glass forming $\mathrm{Zr}_{52.5} \mathrm{Cu}_{17.9} \mathrm{Al}_{10} \mathrm{Ni}_{14.6} \mathrm{Ti}_{5}$ alloy (Vitreloy 105 ) in $0.01 \mathrm{M} \mathrm{Na}_{2} \mathrm{SO}_{4}+0.01 \mathrm{M} \mathrm{NaCl}$ solution. Experiments were carried out on $2 \times 2.5 \times 27 \mathrm{~mm}^{3}$ samples at constant deflection and constant anodic potential. Applied stress values were in the elastic regime, and applied potential values were in the interval between the repassivation and the pitting potential. Deflection, stress, and the current density were monitored in situ during the stress corrosion cracking process. Figure 4 shows exemplarily the evolution of deflection, stress, and current density for one experiment carried out at an initial applied stress of 30\% of the yield strength at $0.2 \%$ offset, and an applied anodic potential of $50 \mathrm{mV} v \mathrm{~s}$. SCE. It can be seen that initially the current density is very low corresponding to a passive state. After a certain incubation time, i.e., in this case $133 \mathrm{~s}$, the current density suddenly increases by several orders of magnitude. 
Since at this moment there is no significant change in the deflection and the stress signals, this sudden current increase is attributed to pitting corrosion. After another $1353 \mathrm{~s}$, the stress starts to decrease signalling the initiation of the cracking process. As the crack propagates, the measured stress level continuously and rapidly decreases down to a value of $645 \mathrm{MPa}$, when catastrophic fracture by unstable crack growth occurs. Experiments performed at various stress and potential levels revealed two clear trends: (1) the time to fracture is shorter (SCC resistance is lower) for higher potentials or higher stresses; (2) the time required by a pit/a group of pits to turn into a crack is shorter at higher stresses.

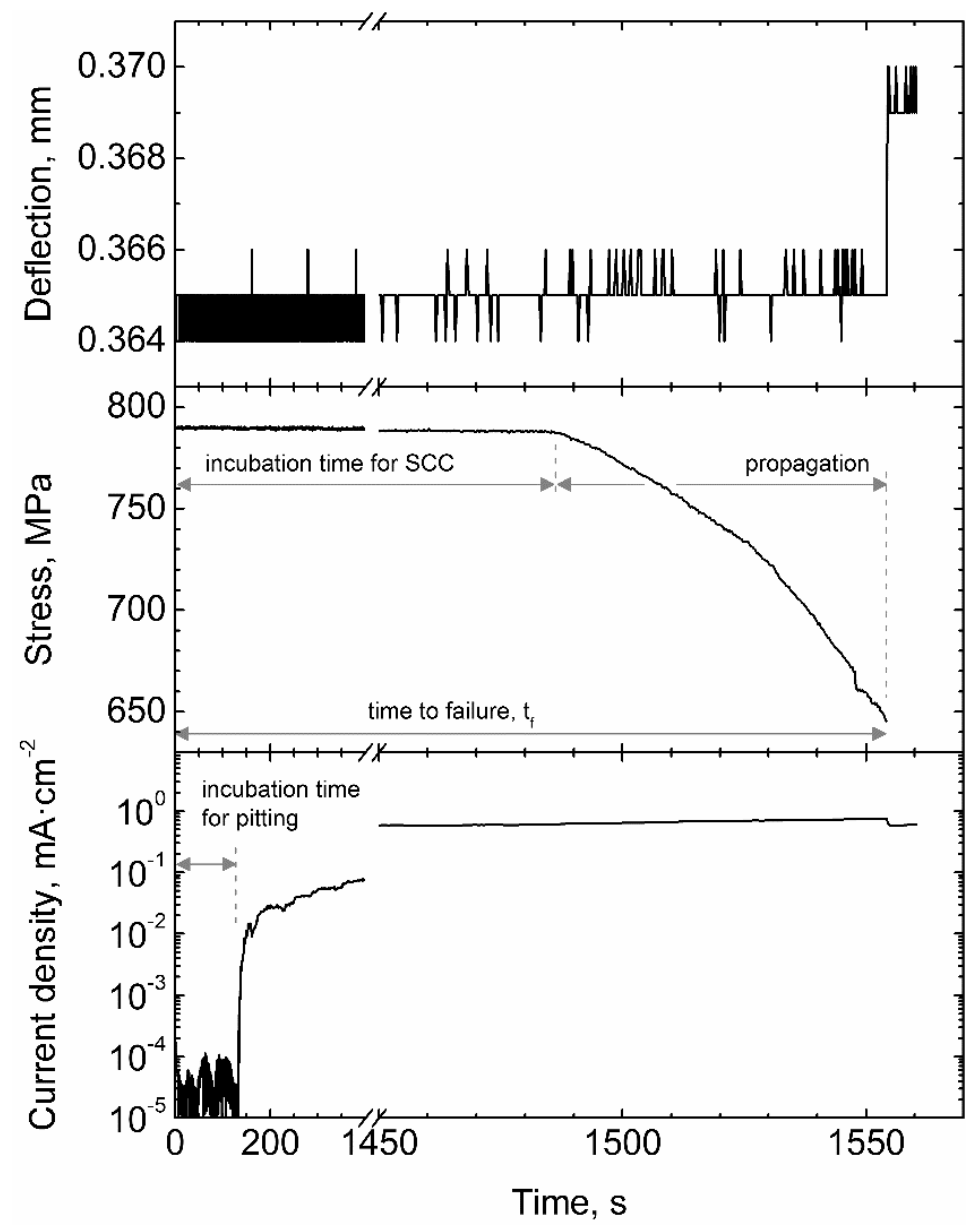

Figure 4. The evolution of deflection, stress, and current density of a bulk glass forming $\mathrm{Zr}_{52.5} \mathrm{Cu}_{17.9} \mathrm{Al}_{10} \mathrm{Ni}_{14.6} \mathrm{Ti}_{5}$ alloy (Vitreloy 105) sample in $0.01 \mathrm{M} \mathrm{Na}_{2} \mathrm{SO}_{4}+0.01 \mathrm{M} \mathrm{NaCl}$ solution under three-point bending at an initial stress of $30 \%$ of the yield strength at $0.2 \%$ offset, and an applied anodic potential of $50 \mathrm{mV} v s$. SCE.

Fractography analysis revealed the presence of multiple pits typically located at sample edges. In all cases, one or more pits were found at the crack initiation location confirming that cracks originate at pits. This is shown in Figure 5a. In the stable crack propagation region of the fracture surface, two different zones were observed. As shown in Figure 5b, close to the lateral side of the fractured bending sample, the crack propagated mostly in a mechanical brittle manner: this zone is characterized by cleavage features and by the absence of corrosion signs. The other zone, which is close to the tension side of the fractured bending sample and shown in Figure 5c, is dominated by fine striations and crack branching. Observation of finer topographical features was impeded due to corrosion. One possible 
mechanism (explaining the striations and crack branches) could comprise alternate crack sharpening by anodic dissolution at the crack tip and crack blunting by formation of shear bands and/or crack branching. Anodic dissolution may take place preferentially along shear bands. As shown in the previous section, pre-formed shear bands can be preferential sites for pitting initiation and continued pit growth.
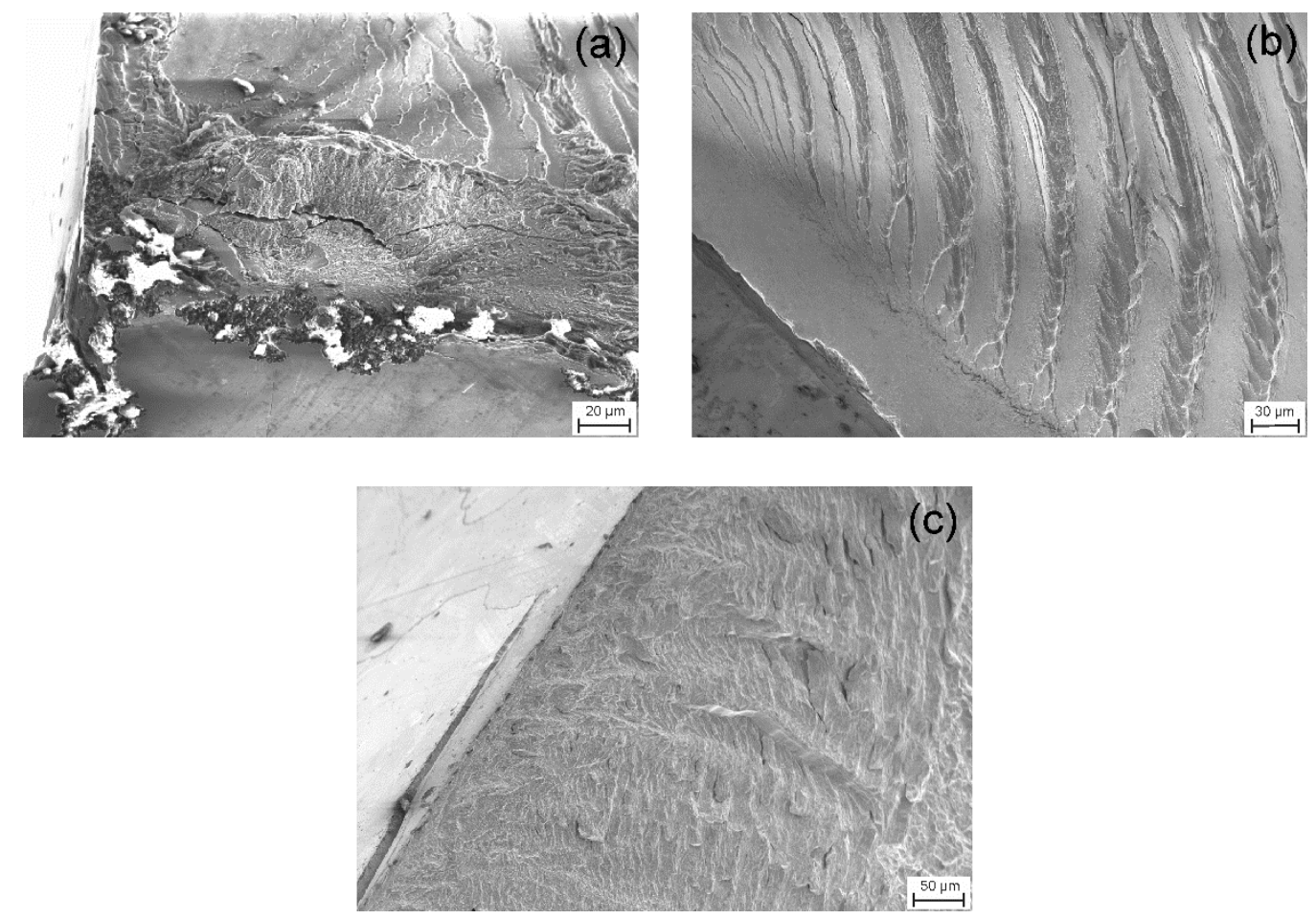

Figure 5. Fracture surface of a bulk glass forming $\mathrm{Zr}_{52.5} \mathrm{Cu}_{17.9} \mathrm{Al}_{10} \mathrm{Ni}_{14.6} \mathrm{Ti}_{5}$ alloy (Vitreloy 105) sample fractured by stress corrosion cracking in $0.01 \mathrm{M} \mathrm{Na}_{2} \mathrm{SO}_{4}+0.01 \mathrm{M} \mathrm{NaCl}$ under three point bending and anodic polarization. (a) Crack initiation location; (b) Stable crack propagation region close to lateral side (perpendicular to tension side) of fractured bending sample; (c) Stable crack propagation region close to tension side of fractured bending sample.

In conclusion, few Zr-based BMGs were investigated regarding their sensitivity to SCC. Those first works demonstrated clearly high susceptibility to SCC in chloride-containing aqueous environments. Pitting is a necessary initial stage and cracking by stress-corrosion interactions initiates at pits. The crack growth rate is usually high and is attributed to active anodic dissolution at the crack tip. However, one study claims hydrogen damage to be responsible for crack propagation. One possible SCC mechanism could consist of alternate crack sharpening by anodic dissolution at the crack tip and crack blunting by formation of shear bands and/or crack branching, but more detailed investigations are needed for a comprehensive description of the SCC mechanism in Zr-based BMGs.

\subsection{Corrosion Fatigue}

Schroeder and Ritchie [54,56] prepared fatigue pre-cracked CT specimen $\left(4.4 \times 20 \times 20 \mathrm{~mm}^{3}\right)$ of the $\mathrm{Zr}_{41.2} \mathrm{Ti}_{13.8} \mathrm{Cu}_{12.5} \mathrm{Ni}_{10} \mathrm{Be}_{22.5} \mathrm{BMG}$ to investigate fatigue crack growth processes under the influence of aqueous media (de-ionized water, $0.5 \mathrm{M} \mathrm{Na}_{2} \mathrm{SO}_{4}$ or $\mathrm{NaClO}_{4}$ solution, $0.005-0.5 \mathrm{M} \mathrm{NaCl}$ solution). Fatigue experiments were conducted under increasing and decreasing range of stress intensity factor $\Delta K$ 
and under constant cyclic loading. A particular sensitivity of the fatigue crack growth to $\mathrm{NaCl}$ solutions under OCP conditions was detected with a crack growth rate being three orders of magnitude higher than that in air. The fatigue crack growth behavior in the $\mathrm{d} a / \mathrm{d} N v s . \Delta K$ plot revealed for the salt solutions a medium-controlled characteristic of an abrupt threshold, whereupon the growth rate increased by 3-5 orders of magnitude to reach a plateau regime (region II) where the crack growth is relatively independent from the stress intensity range. Compared to the fatigue threshold $\Delta K_{\text {th }}$ in air of $3 \mathrm{MPa} \cdot \mathrm{m}^{1 / 2}$, the value was strongly reduced to $\sim 0.9 \mathrm{MPa} \cdot \mathrm{m}^{1 / 2}$ in salt solutions. The constant fatigue crack growth rates in region II were under OCP conditions directly proportional to the $\mathrm{NaCl}$ concentration, whereby $\Delta K_{\text {th }}$ remained nearly constant. Under cathodic control the growth rates decreased, whereby no changes were observed under anodic control in a limited potential window. The poor environmental cracking resistance of this particular BMG was mainly attributed to stress enhanced anodic dissolution at the crack tip.

Morrison et al. [57] employed the $\mathrm{Zr}_{52.5} \mathrm{Cu}_{17.9} \mathrm{Ni}_{14.6} \mathrm{Al}_{10} \mathrm{Ti}_{5}$ (Vitreloy 105) BMG to analyze the corrosion-fatigue behavior in four-point bending tests. They used rectangular specimens $\left(3.5 \times 3.5 \times 30 \mathrm{~mm}^{3}\right)$ and tested them in $0.6 \mathrm{M} \mathrm{NaCl}$ solution. While at stress amplitudes of $\geq 800 \mathrm{MPa}$ the corrosion-fatigue life was similar to that in air, an increasingly deleterious effect of the salt solution was observed as the stress amplitude decreased due to increasing length of exposure time. At $425 \mathrm{MPa}$ the corrosion-fatigue life in $\mathrm{NaCl}$ solution was more than one order of magnitude lower than that in air. The fatigue-endurance limit reached in the salt solution $\sim 50 \mathrm{MPa}$ which relates to a decrease of $\sim 88 \%$. This behavior of the Zr-based BMG was found to be similar to that of crystalline Al. With SEM no significant effect of the test medium on fracture morphology was noticed. Crack initiation occurred on the machined and polished samples preferentially at the outer pins of the tensile surface. The corrosion-fatigue mechanism was concluded to be driven by anodic dissolution with no indication for hydrogen embrittlement.

Wiest et al. [59] used results of this study as reference data for their corrosion-fatigue studies on $\mathrm{Zr}-\mathrm{Ti}(-\mathrm{Co})-$ Be rod samples $(3 \mathrm{~mm}$ diam. $\times 6 \mathrm{~mm}, 2 \mathrm{~mm}$ diam. $\times 4 \mathrm{~mm})$ in compression loading. These alloys with no or low late TM-content exhibit very low corrosion rates and strong barrier-type passive behavior, but a lower pitting resistance than Vitreloy 105. The latter explains their poor corrosion fatigue performance. Huang et al. [60] prepared $\mathrm{Zr}_{55} \mathrm{Cu}_{30} \mathrm{Al}_{10} \mathrm{Ni}_{5}+1$ at. $\% \mathrm{Y}$ rectangular glass samples $\left(3 \times 3 \times 25 \mathrm{~mm}^{3}\right)$ for 4-point-bending in an artificial body fluid. They confirmed a low impact of the medium on fatigue lifetime at high stress ranges $(\geq 450 \mathrm{MPa})$, but a detrimental effect in the lower range. The fatigue strength decreased by $40 \%$ compared to air tests. A degradation mechanism was proposed considering the random formation of a corrosion pit at the tension side, from where crack initiation takes place due to stress concentration and exposure of the bare metal surface. Crack propagation was stated to be driven by anodic dissolution resulting in a rough fracture surface.

All the above-described studies characterized the corrosion fatigue behavior in aqueous environments. However, for Zr-based BMGs ambient air can also cause corrosion fatigue phenomena leading to significant reduction of their fatigue resistance. The extent of degradation of fatigue properties by ambient air is strongly dependent on alloy chemistry. Philo et al. [72] analyzed the fatigue crack growth behavior of $\mathrm{Zr}_{58.5} \mathrm{Cu}_{15.6} \mathrm{Ni}_{12.8} \mathrm{Al}_{10.3} \mathrm{Nb}_{2.8} \mathrm{BMG}$ (Vitreloy 106a), and found a regime in the $\mathrm{d} a / \mathrm{d} N v s . \Delta K$ curve, where the crack growth was relatively independent of $\Delta K$, implying a controlling effect of the ambient air. This plateau occurs at $2.5 \cdot 10^{-8} \mathrm{~m} \cdot \mathrm{cycle}^{-1}$ and is much higher than for $\mathrm{Zr}_{44} \mathrm{Ti}_{11} \mathrm{Ni}_{10} \mathrm{Cu}_{10} \mathrm{Be}_{25} \mathrm{BMG}$ (Vitreloy 1b), i.e., $10^{-9} \mathrm{~m} \cdot \mathrm{cycle}^{-1}$ [73]. It is not yet clear what 
the mechanisms are involved in the observed corrosion fatigue effect in ambient air. Surface oxidation and/or hydrogen embrittlement were suggested as the main reason [9,74]. Studies regarding effects of hydrogen on the fatigue behavior of Zr-based BMGs were presented in the subsection Hydrogen Effects.

In summary, the corrosion fatigue behavior of several Zr-based BMGs was studied and all showed high susceptibility/poor resistance to corrosion fatigue cracking in chloride containing aqueous solutions. Some Zr-based BMGs exhibit a corrosion fatigue effect in ambient air, and this is strongly dependent on alloy chemistry. In chloride containing aqueous solutions, corrosion fatigue crack propagation appears to be controlled by anodic dissolution. It is not yet clear what the main reasons and the underlying mechanisms are for the observed corrosion fatigue phenomena in ambient air.

\section{Outlook}

Those first reported studies reviewed here clearly reveal a high sensitivity of Zr-based bulk metallic glasses to corrosion-deformation interactions in halide-containing aqueous environments. However, tests on these aspects were conducted so far only for a few selected alloy compositions with high GFA, e.g., on special Be-containing glasses, which enable the preparation of glassy samples in larger dimensions needed for tests with CT specimens or bending plates. Moreover, different mechanical loading procedures and conditions were applied under various environmental influences which do not permit a direct comparison of the results and which have led in part to contradicting conclusions. Therefore, more systematic studies are needed for a comprehensive mechanistic description of those environmentally assisted mechanical degradation phenomena. Considering general corrosion and hydrogenation studies, besides structural particularities the glassy alloy composition is expected to play a significant role in environmentally assisted crack initiation and propagation. This refers in particular to the $\mathrm{Cu}$ :valve-metal ratio which controls anodic and cathodic reactions rates. A reliable analysis of those compositional effects is still missing. Furthermore, introduction of finely dispersed heterogeneities into an amorphous phase like clusters/nanocrystals was demonstrated to be a successful strategy to increase macroscopic plasticity under compression or tensile load in air. But there is no clear understanding yet how this affects the environmental-assisted fracture and fatigue behavior. Also, the role of different types of surface defects, e.g., of notches or of micro-indents, is mostly unclear. Altogether, more detailed microscopic and spectroscopic studies of crack regions at different propagation states and of fracture surfaces are needed. These should be focused on analyzing processes on the sub-micron scale like shear band evolution or chemical reactions under the special conditions of highly localized stresses, crevice geometry, and varying media and polarization states. Such knowledge is the pre-requisite for mechanistic models of stress corrosion cracking and corrosion fatigue phenomena and their dependence on structural and compositional particularities of Zr-based bulk metallic glasses.

\section{Acknowledgments}

A. Davenport, J.R. Scully, and N. Birbilis are acknowledged for fruitful discussions. The authors are grateful to M. Frey, S. Donath and M. Johne for technical assistance. Financial support for this work was provided by the German Research Society (DFG) under grants GE 1106/11-1 and KE 1426/4-1 in the frame of the SPP 1594 collaborative project. 


\section{Author Contributions}

P.F.G., M.U., A.G. and E.K. wrote the text. D.E. and D.G. carried out experiments. J.E. supervised the research project.

\section{Conflicts of Interest}

The authors declare no conflict of interest.

\section{References}

1. Suryanarayana, C.; Inoue, A. Bulk Metallic Glasses; CRC Press: Boca Raton, FL, USA, 2011; p. 548.

2. Wondraczek, L.; Mauro, J.C.; Eckert, J.; Kühn, U.; Horbach, J.; Deubener, J.; Rouxel, T. Towards ultrastrong glasses. Adv. Mater. 2011, 23, 4578-4586.

3. Trexler, M.M.; Thadhani, N.N. Mechanical properties of bulk metallic glasses. Prog. Mater. Sci. 2010, 55, 759-839.

4. Cheng, Y.Q.; Cao, A.J.; Sheng, H.W.; Ma, E. Local order influences initiation of plastic flow in metallic glass: Effects of alloy composition and sample cooling history. Acta Mater. 2008, 56, 5263-5275.

5. Eckert, J.; Das, J.; Pauly, S.; Duhamel, C. Processing routes, microstructure and mechanical properties of metallic glasses and their composites. Adv. Eng. Mater. 2007, 9, 443-453.

6. Zhang, Y.; Wang, W.H.; Greer, A.L. Making metallic glasses plastic by control of residual stress. Nat. Mater. 2006, 5, 857-860.

7. Song, K.K.; Pauly, S.; Zhang, Y.; Scudino, S.; Gargarella, P.; Surreddi, K.B.; Kühn, U.; Eckert, J. Significant tensile ductility induced by cold rolling in $\mathrm{Cu}_{47.5} \mathrm{Zr}_{47.5} \mathrm{Al}_{5}$ bulk metallic glass. Intermetallics 2011, 19, 1394-1398.

8. Schuh, C.A.; Hufnagel, T.C.; Ramamurty, U. Mechanical behavior of amorphous alloys. Acta Mater. 2007, 55, 4067-4109.

9. Kruzic, J.J. Understanding the Problem of Fatigue in Bulk Metallic Glasses. Metall. Mater. Trans. A 2011, 42, 1516-1523.

10. Scully, J.R.; Gebert, A.; Payer, J. Corrosion and related mechanical properties of bulk metallic glasses. J. Mater. Res. 2007, 22, 302-313.

11. Bankmann, J.; Pundt, A.; Kirchheim, R. Hydrogen loading behaviour of multi-component amorphous alloys: Model and experiment. J. Alloy. Compd. 2003, 356-357, 566-569.

12. Archer, M.D.; Corke, C.C.; Harji, B.H. The Electrochemical Properties of Metallic Glasses. Electrochim. Acta 1987, 32, 13-26.

13. Scully, J.R.; Lucente, A. Corrosion of Amorphous Metals. In ASM Handbook Volume 13B, Corrosion: Materials; Cramer, S.D., Covino, B.S., Jr., Eds.; ASM International: Materials Park, OH, USA, 2005; Volume 13B, pp. 476-489.

14. Hashimoto, K. Chemical properties. In Amorphous Metallic Alloys; Luborsky, F.E., Ed.; Butterworths: London, UK, 1983; pp. 471-486. 
15. Waseda, Y.; Aust, K.T. Corrosion behaviour of metallic glasses. J. Mater. Sci. 1981, 16, 2337-2359.

16. Wilde, G.; Rosner, H. Nanocrystallization in a shear band: An in situ investigation. Appl. Phys. Lett. 2011, doi:10.1063/1.3602315.

17. Wang, L.; Bei, H.; Gao, Y.F.; Lu, Z.P.; Nieh, T.G. Effect of residual stresses on the hardness of bulk metallic glasses. Acta Mater. 2011, 59, 2858-2864.

18. Zhao, J.X.; Wu, F.F.; Zhang, Z.F. Analysis on shear deformation mechanism of metallic glass under confined bending test. Mater. Sci. Eng. A 2010, 527, 6224-6229.

19. Scudino, S.; Jerliu, B.; Pauly, S.; Surreddi, K.B.; Kühn, U.; Eckert, J. Ductile bulk metallic glasses produced through designed heterogeneities. Scr. Mater. 2011, 65, 815-818.

20. Newman, R.C. Stress-Corrosion Cracking Mechanisms. In Corrosion Mechanisms in Theory and Practice, 3rd ed.; Marcus, P., Ed.; CRC Press: Boca Raton, FL, USA, 2011; pp. 499-544.

21. Clarke, D.R.; Faber, K.T. Fracture of ceramics and glasses. J. Phys. Chem. Solids 1987, 48, 1115-1157.

22. Lewandowski, J.J.; Wang, W.H.; Greer, A.L. Intrinsic plasticity or brittleness of metallic glasses. Philos. Mag. Lett. 2005, 85, 77-87.

23. Gebert, A.; Gostin, P.F.; Schultz, L. Effect of surface finishing of a Zr-based bulk metallic glass on its corrosion behaviour. Corros. Sci. 2010, 52, 1711-1720.

24. Huang, L.; Yokoyama, Y.; Wu, W.; Liaw, P.K.; Pang, S.J.; Inoue, A.; Zhang, T.; He, W. Ni-free $\mathrm{Zr}-\mathrm{Cu}-\mathrm{Al}-\mathrm{Nb}-\mathrm{Pd}$ bulk metallic glasses with different $\mathrm{Zr} / \mathrm{Cu}$ ratios for biomedical applications. J. Biomed. Mater. Res. B 2012, 100B, 1472-1482.

25. Lu, H.B.; Zhang, L.C.; Gebert, A.; Schultz, L. Pitting corrosion of $\mathrm{Cu}-\mathrm{Zr}$ metallic glasses in hydrochloric acid solutions. J. Alloys Compd. 2008, 462, 60-67.

26. Pang, S.J.; Zhang, T.; Kimura, H.; Asami, K.; Inoue, A. Corrosion Behavior of $\mathrm{Zr}-(\mathrm{Nb}-) \mathrm{Al}-\mathrm{Ni}-\mathrm{Cu}$ Glassy Alloys. Mater. Trans. JIM 2000, 41, 1490-1494.

27. Pang, S.J.; Zhang, T.; Asami, K.; Inoue, A. Formation, corrosion behavior, and mechanical properties of bulk glassy Zr-Al-Co-Nb alloys. J. Mater. Res. 2003, 18, 1652-1658.

28. Raju, V.R.; Kühn, U.; Wolff, U.; Schneider, F.; Eckert, J.; Reiche, R.; Gebert, A. Corrosion behaviour of Zr-based bulk glass-forming alloys containing $\mathrm{Nb}$ or Ti. Mater. Lett. 2002, 57, 173-177.

29. Li, Y.H.; Zhang, W.; Dong, C.; Qiang, J.B.; Fukuhara, M.; Makino, A.; Inoue, A. Effects of Ni addition on the glass-forming ability, mechanical properties and corrosion resistance of $\mathrm{Zr}-\mathrm{Cu}-\mathrm{Al}$ bulk metallic glasses. Mater. Sci. Eng. A 2011, 528, 8551-8556.

30. Gostin, P.F.; Eigel, D.; Grell, D.; Eckert, J.; Kerscher, E.; Gebert, A. Comparing the pitting corrosion behavior of prominent Zr-based bulk metallic glasses. J. Mater. Res. 2015, 30, 233-241.

31. Gebert, A.; Buchholz, K.; Leonhard, A.; Mummert, K.; Eckert, J.; Schultz, L. Investigations on the electrochemical behaviour of Zr-based bulk metallic glasses. Mater. Sci. Eng. A 1999, 267, 294-300.

32. Paillier, J.; Mickel, C.; Gostin, P.F.; Gebert, A. Characterization of corrosion phenomena of $\mathrm{Zr}-\mathrm{Ti}-\mathrm{Cu}-\mathrm{Al}-\mathrm{Ni}$ metallic glass by SEM and TEM. Mater. Charact. 2010, 61, 1000-1008. 
33. Jones, R.H. Stress-Corrosion Cracking. In ASM Handbook Volume 13A, Corrosion: Fundamentals, Testing and Protection; Cramer, S.D., Covino, B.S., Jr., Eds.; ASM International: Materials Park, OH, USA, 2003; Volume 13A, pp. 346-366.

34. Gebert, A.; Gostin, P.F.; Uhlemann, M.; Eckert, J.; Schultz, L. Interactions between mechanically generated defects and corrosion phenomena of Zr-based bulk metallic glasses. Acta Mater. 2012, 60, 2300-2309.

35. Mear, F.O.; Vaughan, G.; Yavari, A.R.; Greer, A.L. Residual-stress distribution in shot-peened metallic-glass plate. Philos. Mag. Lett. 2008, 88, 757-766.

36. Gebert, A.; Concustell, A.; Greer, A.L.; Schultz, L.; Eckert, J. Effect of shot-peening on the corrosion resistance of a Zr-based bulk metallic glass. Scr. Mater. 2010, 62, 635-638.

37. Pampillo, C.A.; Chen, H.S. Comprehensive Plastic-Deformation of a Bulk Metallic Glass. Mater. Sci. Eng. 1974, 13, 181-188.

38. Guo, H.; Wen, J.; Xiao, N.M.; Zhang, Z.F.; Sui, M.L. The more shearing, the thicker shear band and heat-affected zone in bulk metallic glass. J. Mater. Res. 2008, 23, 2133-2138.

39. Greer, A.L.; Cheng, Y.Q.; Ma, E. Shear bands in metallic glasses. Mat. Sci. Eng. R 2013, 74, 71-132.

40. Gutman, E.M. Mechanochemistry of Materials; Cambridge International Science Publishing: Cambridge, UK, 1998.

41. Nie, X.P.; Cao, Q.P.; Wu, Z.F.; Ma, Y.; Wang, X.D.; Ding, S.Q.; Jiang, J.Z. The pitting corrosion behavior of shear bands in a Zr-based bulk metallic glass. Scr. Mater. 2012, 67, 376-379.

42. Wang, Y.M.; Zhang, C.; Liu, Y.; Chan, K.C.; Liu, L. Why does pitting preferentially occur on shear bands in bulk metallic glasses? Intermetallics 2013, 42, 107-111.

43. Grell, D.; Gostin, P.F.; Eckert, J.; Gebert, A.; Kerscher, E. In situ electrochemical analysis during deformation of a Zr-based bulk metallic glass: A sensitive tool revealing early shear banding. Adv. Eng. Mater. 2015, accepted.

44. Suh, D.; Dauskardt, R.H. Hydrogen effects on the mechanical and fracture behavior of a Zr-Ti-Ni-Cu-Be bulk metallic glass. Scr. Mater. 2000, 42, 233-240.

45. Suh, D.; Dauskardt, R.H. The effects of hydrogen on deformation and fracture of a Zr-Ti-Ni-Cu-Be bulk metallic glass. Mater. Sci. Eng. A 2001, 319, 480-483.

46. Suh, D.; Dauskardt, R.H. Effects of pre-charged hydrogen on the mechanical and thermal behavior of $\mathrm{Zr}-\mathrm{Ti}-\mathrm{Ni}-\mathrm{Cu}-\mathrm{Be}$ bulk metallic glass alloys. Mater. Trans. 2001, 42, 638-641.

47. Daewoong, S.; Asoka-Kumar, P.; Dauskardt, R.H. The effects of hydrogen on viscoelastic relaxation in $\mathrm{Zr}-\mathrm{Ti}-\mathrm{Ni}-\mathrm{Cu}-\mathrm{Be}$ bulk metallic glasses: Implications for hydrogen embrittlement. Acta Mater. 2002, 50, 537-551.

48. Shan, G.B.; Wang, Y.W.; Chu, W.Y.; Li, J.X.; Hui, X.D. Hydrogen damage and delayed fracture in bulk metallic glass. Corros. Sci. 2005, 47, 2731-2739.

49. Shan, G.B.; Wei, B.C.; Li, J.X.; Qiao, L.J.; Chu, W.Y. Effects of hydrogen on shear bands and cracking in Zr base bulk amorphous alloy. Acta Metall. Sin. 2006, 42, 689-693.

50. Jayalakshmi, S.; Kim, K.B.; Fleury, E. Effect of hydrogenation on the structural, thermal and mechanical properties of $\mathrm{Zr}_{50} \mathrm{Ni}_{27} \mathrm{Nb}_{18} \mathrm{Co} 5$ amorphous alloy. J. Alloy. Compd. 2006, 417, 195-202.

51. Shan, G.B.; Li, J.X.; Yang, Y.Z.; Qiao, L.J.; Chu, W.Y. Hydrogen-enhanced plastic deformation during indentation for bulk metallic glass of $\mathrm{Zr}_{65} \mathrm{Al}_{7.5} \mathrm{Ni}_{10} \mathrm{Cu}_{17.5}$. Mater. Lett. 2007, 61, 1625-1628. 
52. Dong, F.Y.; Su, Y.Q.; Luo, L.S.; Wang, L.; Wang, S.J.; Guo, L.J.; Fu, H.Z. Enhanced plasticity in Zr-based bulk metallic glasses by hydrogen. Int. J. Hydrog. Energy 2012, 37, 14697-14701.

53. Ritchie, R.O.; Schroeder, V.; Gilbert, C.J. Fracture, fatigue and environmentally-assisted failure of a Zr-based bulk amorphous metal. Intermetallics 2000, 8, 469-475.

54. Schroeder, V.; Gilbert, C.J.; Ritchie, R.O. A comparison of the mechanisms of fatigue-crack propagation behavior in a $\mathrm{Zr}$-based bulk amorphous metal in air and an aqueous chloride solution. Mater. Sci. Eng. A 2001, 317, 145-152.

55. Schroeder, V.; Gilbert, C.J.; Ritchie, R.O. Effect of aqueous environment on fatigue-crack propagation behavior in a Zr-based bulk amorphous metal. Scr. Mater. 1999, 40, 1057-1061.

56. Schroeder, V.; Ritchie, R.O. Stress-corrosion fatigue-crack growth in a Zr-based bulk amorphous metal. Acta Mater. 2006, 54, 1785-1794.

57. Morrison, M.L.; Buchanan, R.A.; Liaw, P.K.; Green, B.A.; Wang, G.Y.; Liu, C.T.; Horton, J.A. Corrosion-fatigue studies of the Zr-based Vitreloy 105 bulk metallic glass. Mater. Sci. Eng. A 2007, 467, 198-206.

58. Nakai, Y.; Yoshioka, Y. Stress Corrosion and Corrosion Fatigue Crack Growth of Zr-Based Bulk Metallic Glass in Aqueous Solutions. Metall. Mater. Trans. A 2010, 41A, 1792-1798.

59. Wiest, A.; Wang, G.Y.; Huang, L.; Roberts, S.; Demetriou, M.D.; Liaw, P.K.; Johnson, W.L. Corrosion and corrosion fatigue of Vitreloy glasses containing low fractions of late transition metals. Scr. Mater. 2010, 62, 540-543.

60. Huang, L.; Wang, G.Y.; Qiao, D.C.; Liaw, P.K.; Pang, S.J.; Wang, J.F.; Zhang, T. Corrosion-fatigue study of a Zr-based bulk-metallic glass in a physiologically relevant environment. J. Alloy. Compd. 2010, 504, S159-S162.

61. Gostin, P.F.; Eigel, D.; Grell, D.; Uhlemann, M.; Kerscher, E.; Eckert, J.; Gebert, A. Stress corrosion cracking of a Zr-based bulk metallic glass. Mater. Sci. Eng. A 2015, 639, 681-690.

62. Craig, B. Introduction to Environmentally Induced Cracking. In ASM Handbook; Cramer, S.D., Covino, B.S.J., Eds.; ASM International: Materials Park, OH, USA, 2003; Volume 13A, p. 345.

63. Mattern, N.; Gebert, A. Hydrogenation of $\mathrm{Zr}_{60} \mathrm{Ti}_{2} \mathrm{Cu}_{20} \mathrm{Al}_{10 \mathrm{Ni}}$ bulk metallic glass. Appl. Phys. Lett. 2003, 83, 1134-1135.

64. Mizubayashi, H.; Shibasaki, M.; Murayama, S. Local strain around hydrogen in amorphous $\mathrm{Cu}_{50} \mathrm{Zr}_{50}$ and $\mathrm{Cu}_{50} \mathrm{Ti}_{50}$. Acta Mater. 1999, 47, 3331-3338.

65. Hasegawa, M.; Kotani, K.; Yamaura, S.; Kato, H.; Kodama, I.; Inoue, A. Hydrogen-induced internal friction of Zr-based bulk glassy alloys in a rod shape above 90 K. J. Alloys Compd. 2004, 365, 221-227.

66. Rodmacq, B.; Maret, M.; Laugier, J.; Billard, L.; Chamberod, A. Hydrogen-Induced Phase-Separation in Amorphous Cu0.5Ti0.5 Alloys. 1. Room-Temperature Experiments. Phys. Rev. B 1988, 38, 1105-1115.

67. Ismail, N.; Gebert, A.; Uhlemann, M.; Eckert, J.; Schultz, L. Effect of hydrogen on

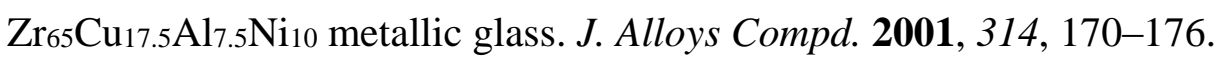

68. Ismail, N.; Uhlemann, M.; Gebert, A.; Eckert, J. Hydrogenation and its effect on the crystallisation behaviour of $\mathrm{Zr}_{55} \mathrm{Cu}_{30} \mathrm{Al}_{10} \mathrm{Ni}{ }_{5}$ metallic glass. J. Alloys Compd. 2000, 298, 146-152.

69. Yoo, B.G.; Oh, J.H.; Kim, Y.J.; Jang, J.I. Effect of hydrogen on subsurface deformation during indentation of a bulk metallic glass. Intermetallics 2010, 18, 1872-1875. 
70. Wang, Y.W.; Chu, W.Y.; Li, J.X.; Hui, X.D.; Wang, Y.; Gao, K.W.; Su, Y.J.; Qiao, L.J. In situ observation of hydrogen-enhanced localized plastic flow in Zr-based bulk metallic glass. Mater. Lett. 2004, 58, 2393-2396.

71. Kawashima, A.; Yokoyama, Y.; Inoue, A. Zr-based bulk glassy alloy with improved resistance to stress corrosion cracking in sodium chloride solutions. Corros. Sci. 2010, 52, 2950-2957.

72. Philo, S.L.; Heinrich, J.; Gallino, I.; Busch, R.; Kruzic, J.J. Fatigue crack growth behavior of a $\mathrm{Zr}_{58.5} \mathrm{Cu}_{15.6} \mathrm{Ni}_{12.8} \mathrm{Al}_{10.3} \mathrm{Nb}_{2.8}$ bulk metallic glass-forming alloy. Scr. Mater. 2011, 64, 359-362.

73. Launey, M.E.; Busch, R.; Kruzic, J.J. Effects of free volume changes and residual stresses on the fatigue and fracture behavior of a $\mathrm{Zr}-\mathrm{Ti}-\mathrm{Ni}-\mathrm{Cu}-\mathrm{Be}$ bulk metallic glass. Acta Mater. 2008, 56, 500-510.

74. Philo, S.L.; Kruzic, J.J. Fatigue crack growth behavior of a $\mathrm{Zr}-\mathrm{Ti}-\mathrm{Cu}-\mathrm{Ni}-\mathrm{Be}$ bulk metallic glass: Role of ambient air environment. Scr. Mater. 2010, 62, 473-476.

(C) 2015 by the authors; licensee MDPI, Basel, Switzerland. This article is an open access article distributed under the terms and conditions of the Creative Commons Attribution license (http://creativecommons.org/licenses/by/4.0/). 